\title{
Western U.S. Extreme Precipitation Events and Their Relation to ENSO and PDO in CCSM4
}

\author{
Michael J. DeFlorio And DAvid W. Pierce \\ Division of Climate, Atmospheric Sciences, and Physical Oceanography, Scripps Institution of Oceanography, \\ La Jolla, California \\ DANIEL R. CAYAN \\ Division of Climate, Atmospheric Sciences, and Physical Oceanography, Scripps Institution of Oceanography, \\ and Water Resources Discipline, U.S. Geological Survey, La Jolla, California \\ ARTHUR J. MiLLER \\ Division of Climate, Atmospheric Sciences, and Physical Oceanography, Scripps Institution of Oceanography, \\ La Jolla, California
}

(Manuscript received 4 May 2012, in final form 12 December 2012)

\begin{abstract}
Water resources and management over the western United States are heavily impacted by both local climate variability and the teleconnected responses of precipitation to the El Niño-Southern Oscillation (ENSO) and Pacific decadal oscillation (PDO). In this work, regional precipitation patterns over the western United States and linkages to ENSO and the PDO are analyzed using output from a Community Climate System Model version 4 (CCSM4) preindustrial control run and observations, with emphasis on extreme precipitation events. CCSM4 produces realistic zonal gradients in precipitation intensity and duration over the western United States, with higher values on the windward side of the Cascade Mountains and Sierra Nevada and lower values on the leeward. Compared to its predecessor CCSM3, CCSM4 shows an improved teleconnected signal of both ENSO and the PDO to large-scale circulation patterns over the Pacific-North America region and also to the spatial pattern and other aspects of western U.S. precipitation. The so-called drizzle problem persists in CCSM4 but is significantly improved compared to CCSM3. In particular, it is found that CCSM4 has substantially less precipitation duration bias than is present in CCSM3. Both the overall and extreme intensity of wintertime precipitation over the western United States show statistically significant linkages with ENSO and PDO in CCSM4. This analysis provides a basis for future studies using greenhouse gas (GHG)-forced CCSM4 runs.
\end{abstract}

\section{Introduction}

Water resources have extensive influence on government policy, quality of life, and regional economics. This is particularly true over the western United States, which harbors a rapidly growing population, very active climate variability, and complex topography that affects regional climate including the spatial and temporal structure of precipitation. The generally arid southwestern United States, which is the fastest growing

Corresponding author address: Michael J. DeFlorio, Scripps Institution of Oceanography, 9500 Gilman Dr., Mail Code 0208, La Jolla, CA 92093.

E-mail: mdeflori@ucsd.edu region of the United States, is one area where effective water management is of paramount importance (e.g., Parker 2010). The Pacific Northwest is influenced by interannual and interdecadal climate variation (Hamlet and Lettenmaier 1999). In addition, flooding has major impacts in the region, and is an important player in regional economic policy, particularly in California (Ralph 2012). For example, in 2010, the Federal Emergency Management Agency forced homeowners in Los Angeles, Orange, Ventura, Riverside, and San Bernardino counties to buy flood insurance because of their proximity to flood-prone rivers and creeks (Saillant 2010).

Synoptic weather patterns over the western United States are known to be influenced by the El NiñoSouthern Oscillation (ENSO) and the Pacific decadal 
oscillation (PDO). The teleconnected signal of ENSO in climatic variables across the globe has been an important topic of research for many decades (e.g., Bjerknes 1969; Trenberth 1976; Rasmusson and Wallace 1983; Ropeleweski and Halpert 1986; Bradley et al. 1987; McCabe and Dettinger 1999; Meehl et al. 2007). Many coupled GCMs have exhibited unrealistic teleconnections between ENSO fluctuations and extratropical circulation patterns, in part from having poorly represented physical processes in the core ENSO region (Solomon et al. 2007; AchutaRao and Sperber 2006; Zhu et al. 2004). The warm and cool phases of the PDO are also associated with distinctly different western U.S. weather patterns (Hidalgo and Dracup 2003), despite the lack of robust evidence for physical causality of decadal North Pacific SST variability (Pierce 2002).

The present climatological study investigates the National Center for Atmospheric Research (NCAR) Community Climate System Model, version 4 (CCSM4) skill in simulating several teleconnected signals of ENSO and the PDO over the North Pacific, extreme regional precipitation over the western United States and North Pacific, and the relationship of the phase of both ENSO and the PDO to western U.S. extreme precipitation. We also compare CCSM4 to results from CCSM3 (the previous version of the model) and observations.

Extending prior work evaluating GCM simulations of ENSO and PDO teleconnections and regional precipitation events to CCSM4 is timely, since the model was released recently and will be used in the upcoming fifth Intergovernmental Panel on Climate Change (IPCC) assessment, and is important to the applications noted above. The model's simulation of interannual climatic variability, as captured in the frequency of ENSO events, is more realistic than that of its predecessor, CCSM3; however, the magnitude of these events is too large compared to observations (Gent et al. 2011; Deser et al. 2012). The improvement in the frequency of ENSO events is primarily due to improvements in the atmospheric convection parameterization scheme (Gent et al. 2011; Neale et al. 2008). Better parameterizations of cloud physics and atmospheric radiation have also improved simulations of precipitation type and amount (Neale et al. 2013). Given these improvements in simulation of largescale decadal coupled ocean-atmospheric processes, which have significant impacts on the strength, frequency, and location of midlatitude synoptic storms, and in small-scale moisture microphysics, it is reasonable to consider the model as a viable candidate for realistically simulating global ENSO and PDO teleconnection patterns and extreme regional precipitation events.

Previous work has addressed GCM simulations of Pacific variability and mean and extreme precipitation characteristics in various ways. Dai (2006) used monthly and 3-hourly data from 18 coupled GCMs (of which CCSM3 was one) to examine patterns of global precipitation intensity and frequency, with particular emphasis on tropical Pacific variability and the simulated partitioning of precipitation between large-scale and convective processes. Notably, they found that most models underestimate the contribution to total precipitation and frequency for heavy precipitation and overestimate them for light precipitation. This is often referred to as the "drizzle problem" of GCMs (Dai 2006; Lee et al. 2009). Wehner et al. (2010) examined the effect of varying horizontal resolution on the ability of CAM3 (Community Atmosphere Model, version 3.0; the atmospheric component of CCSM3) to simulate annual precipitation maxima over the continental United States. They found that model fidelity was a strong function of horizontal resolution; specifically, a resolution of $0.5^{\circ} \times$ $0.625^{\circ}$ allowed for adequate simulation of extreme precipitation events. However, such a resolution is computationally expensive for long climate simulations, especially on a global scale.

This study aims to build on these prior works by investigating CCSM4's representation of mean and extreme precipitation events and ENSO and PDO teleconnections, with a focus on the western United States and North Pacific. Besides comparing to observations, many of the CCSM4 results are compared to simulations by its predecessor CCSM3. Several concluding analyses specifically compare various measures of or relating to precipitation in CCSM4 with observations, since CCSM4 proves to be superior in many ways to CCSM3 in comparison to observations. Particular emphasis will be placed on precipitation duration and intensity over the western United States.

\section{Models and data}

Below, we describe the models and data used in our study. A summary of all models and data is included in Table 1.

\section{a. CCSM4 model runs}

We use a 1300-yr preindustrial control CCSM4 simulation with monthly data and a horizontal resolution of $1.25^{\circ}$ longitude $\times 0.9^{\circ}$ latitude. This run is used to examine ENSO-PDO teleconnection patterns over the western United States and North Pacific. We also use a 150-yr subset of this run with daily data to examine mean and extreme precipitation statistics and their relationship to ENSO and the PDO. Data were obtained from the Earth System Grid website (www. earthsystemgrid.org). 
TABLE 1. List of modeled and observational datasets, and associated characteristics, used in this study.

\begin{tabular}{|c|c|c|c|c|c|}
\hline Dataset & Type & $\begin{array}{l}\text { Horizontal } \\
\text { resolution }\end{array}$ & $\begin{array}{l}\text { Temporal } \\
\text { resolution }\end{array}$ & Length (yr) & Used for \\
\hline $\begin{array}{l}\text { CCSM4 preindustrial } \\
\text { control }\end{array}$ & Model & $1.25^{\circ}$ lon $\times 0.9^{\circ}$ lat & $\begin{array}{l}\text { Monthly } \\
\text { and daily }\end{array}$ & $\begin{array}{l}1300 \text { (monthly); } \\
150 \text { (daily) }\end{array}$ & $\begin{array}{l}\text { ENSO-PDO } \\
\text { teleconnection patterns } \\
\text { and precipitation statistics }\end{array}$ \\
\hline $\begin{array}{l}\text { CCSM3 preindustrial } \\
\text { control }\end{array}$ & Model & T85 & Monthly & 500 & $\begin{array}{l}\text { ENSO-PDO teleconnection } \\
\text { patterns }\end{array}$ \\
\hline $\begin{array}{l}\text { CCSM3 preindustrial } \\
\text { control }\end{array}$ & Model & T85 & Daily & 50 & Precipitation statistics \\
\hline $\begin{array}{l}\text { Hamlet and } \\
\text { Lettenmaier (2005) }\end{array}$ & Obs & $0.125^{\circ}$ lat $\times 0.125^{\circ}$ lon & Daily & 53 & Precipitation statistics \\
\hline $\begin{array}{l}\text { da Silva/National } \\
\quad \text { Meteorological Center }\end{array}$ & Obs & $1^{\circ}$ lat $\times 1^{\circ}$ lon & Monthly & 52 & $\begin{array}{l}\text { ENSO-PDO teleconnection } \\
\text { patterns }\end{array}$ \\
\hline
\end{tabular}

\section{b. CCSM3 model runs}

To evaluate improvements in CCSM4's simulation of ENSO-PDO teleconnection patterns and extreme precipitation events, we also use 500 years of monthly data and 50 years of daily data from a preindustrial control $\mathrm{CCSM} 3$ simulation at $\mathrm{T} 85$ resolution $\left(1.4^{\circ}\right.$ longitude $\times 1.4^{\circ}$ latitude). This run is similarly used to examine ENSOPDO teleconnection patterns over the western United States and North Pacific and western U.S. precipitation.

\section{c. Observational data}

When comparing model precipitation fields to observations, one must distinguish between results obtained at a point (station data) and results averaged over an area. The distinction arises because model grid cells, even at T85 resolution, are considerably larger than the length scales associated with patches of heavy precipitation. The most appropriate way to think about model precipitation may be to view it as an area-averaged quantity, rather than as a model representation of precipitation at a point (Chen and Knutson 2008). This suggests that observed gridded precipitation fields, not station data, are preferable for validating model results. We compare the model results to the gridded observed precipitation dataset of Hamlet and Lettenmaier (2005). This is a daily gridded dataset based on National Weather Service cooperative stations, augmented by higher-quality Global Historical Climatology Network and other stations. Techniques from the Parameter-Elevation Regressions on Independent Slopes Model (PRISM) project are used to interpolate the observations over the entire domain while accounting for elevation and slope aspect effects (Daly et al. 1994, 2002). This dataset is produced on a $1 / 8^{\circ} \times 1 / 8^{\circ}$ grid and spans the period 1915-2002. However, since meteorological station coverage increased substantially after World War II, the period analyzed here in 1950-2002. Cayan et al. (2010) found that when the Hamlet and Lettenmaier dataset is used to drive the Variable Infiltration Capacity (VIC) hydrological model, the simulated streamflows are realistic when compared to the available observations, which suggests that the data are capturing the features of observed precipitation relevant to hydrology.

For observations of sea surface temperature (SST), a combined dataset is used: the da Silva data over the period 1948-82 (da Silva et al. 1994) and the National Meteorological Center data from 1983 through the end of 2009 (Reynolds et al. 2002). We choose to analyze only post-World War II SST data because the density of available observations over the North Pacific is much higher during this time period. In addition, it is desirable to have precipitation and sea surface temperature datasets that are of comparable length.

\section{d. Regridding}

To compare with the GCM output, the observational data were regridded to match the grid of the GCM (Chen and Knutson 2008). Aggregating the finer observed data (i.e., regridding from high resolution to low resolution) smoothes the high-density observed data over the region of interest, but is necessary for the matching the coarser topography representation in the GCM. The finer observed datasets are regridded to match the coarser CCSM4 daily model data grid, using a bilinear interpolation scheme. Equating the grid sizes of the modeled and observed datasets enables easier comparison of differences in modeled and observed precipitation.

\section{e. Precipitation terminology}

We define several terms related to mean and extreme precipitation statistics that will be used throughout the rest of this study: a precipitating day, precipitation intensity, and precipitation duration. Given the model issues with drizzle noted previously, we define a 

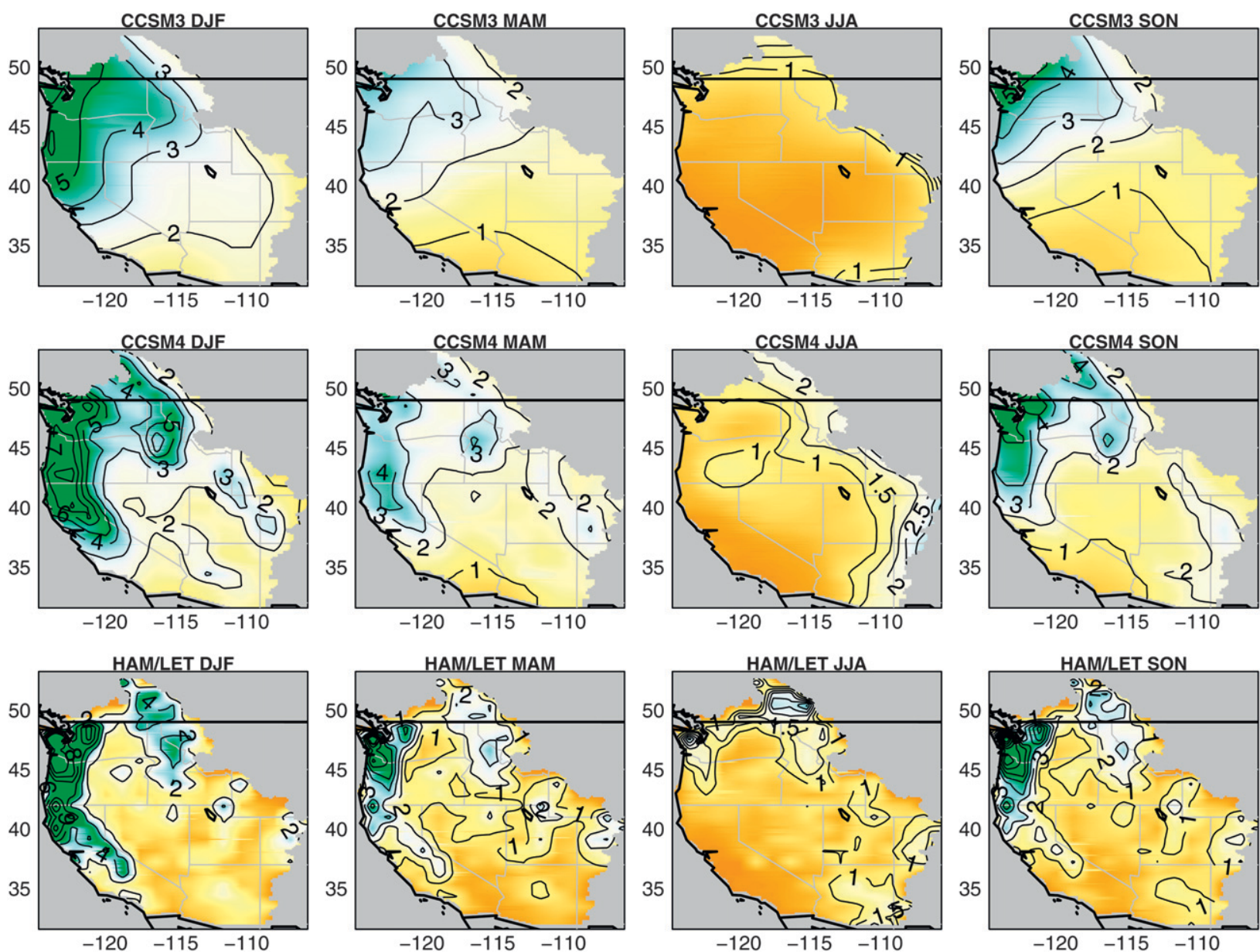

FIG. 1. (from left to right) Seasonal [December-February (DJF), March-May (MAM), June-August (JJA), and September-November (SON)] climatology of precipitation $\left(\mathrm{mm} \mathrm{day}^{-1}\right.$ ) for (from top to bottom) CCSM3, CCSM4, and observations; contour intervals are every $1 \mathrm{~mm}$ day $^{-1}$. CCSM4 shows improvement in capturing the strong observed zonal gradient in precipitation over the western United States.

"precipitating day" as a day on which precipitation totaling $>0.1 \mathrm{~mm} \mathrm{day}^{-1}$ falls. "Precipitation intensity" is defined as the daily value of precipitation rate $\left(\mathrm{mm} \mathrm{day}{ }^{-1}\right)$ over a grid cell on a precipitating day. "Precipitation duration" is defined as the number of consecutive precipitating days.

\section{Western U.S. precipitation climatology}

\section{a. Base seasonal climatology}

Figure 1 shows the seasonal climatology of mean precipitation for the Hamlet and Lettenmaier dataset compared to both CCSM3 monthly data at T85 $\left(\sim 1.4^{\circ}\right)$ resolution and CCSM4 daily data at $\sim 1.25^{\circ}$ latitude $\times$ $0.9^{\circ}$ longitude resolution. It is clear that climatological precipitation is more realistic in CCSM4, both in spatial structure and seasonal agreement with observations. Some of this improvement may be due to the slightly finer grid used by CCSM4 compared to CCSM3. In particular,
CCSM4 does a better job simulating the magnitude and spatial structure of several important features during the wet (September-February) season, including the large Pacific Northwest-Northern California zonal gradient in precipitation and the circular "bull's-eye" pattern of enhanced precipitation over north central Idaho. The former feature can be attributed to the presence of the Cascade Mountains and northern Sierra Nevada; the latter feature is likely due to large height gradients caused by the meeting of the Snake River Plain and the Salmon River Mountains. Thus, CCSM4 demonstrates regional dexterity in simulating orographically enhanced precipitation across the domain. In comparison, CCSM4's predecessor, CCSM3, smeared the Pacific Northwest precipitation gradient over a wide region and was unable to capture the complex precipitation response over central Idaho. One deficiency in CCSM4's simulation is that it is drier than observations over the Pacific Northwest by several millimeters per day during the winter. 

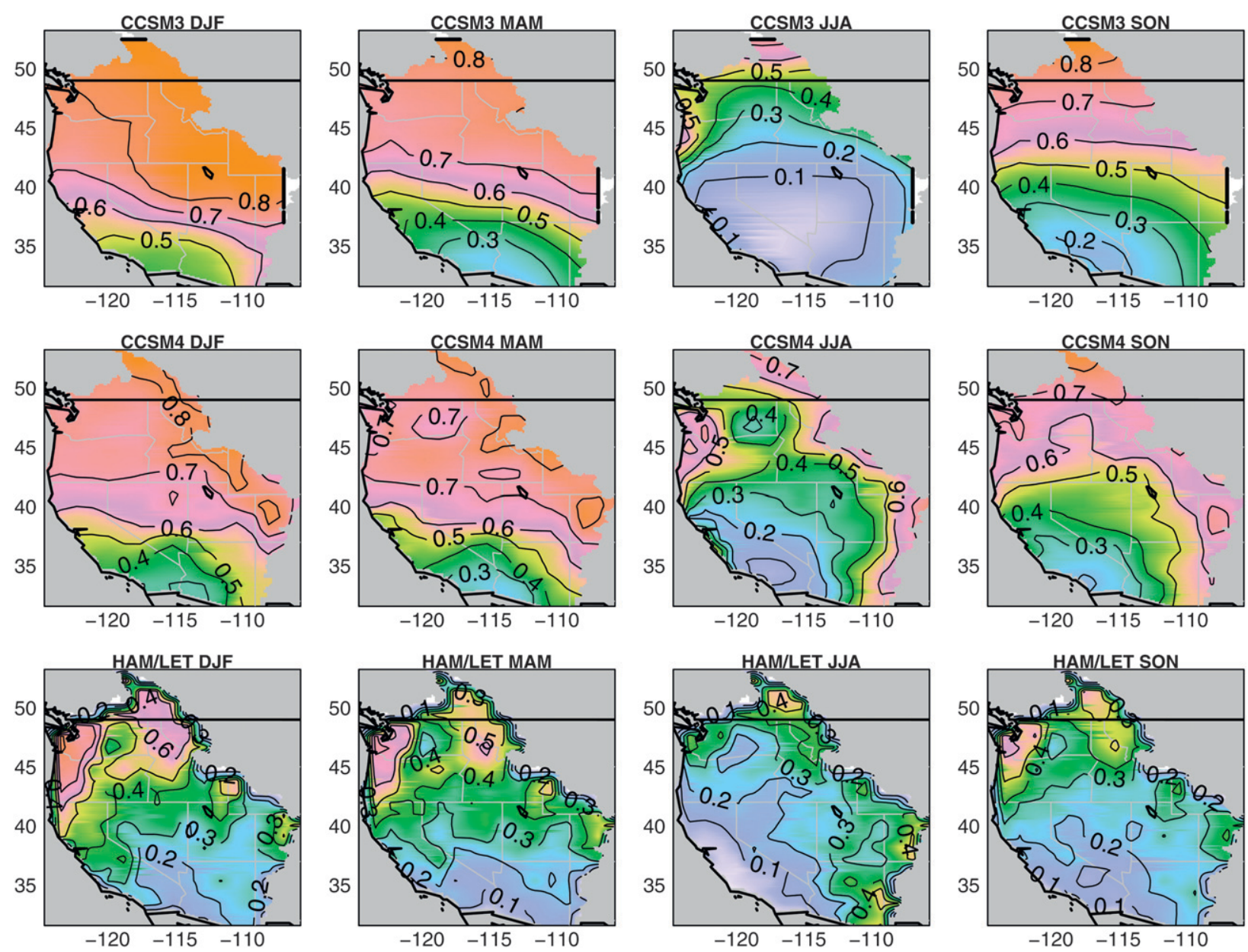

FIG. 2. As in Fig. 1, but for the fraction of precipitating days $\left(>0.1 \mathrm{~mm} \mathrm{day}^{-1}\right)$. Both CCSM3 and CCSM4 exhibit wet biases across much of the domain during all seasons.

\section{b. Fraction of precipitating days}

As mentioned earlier, the drizzle problem of GCMs is a major barrier to realistic simulations of regional precipitation patterns. This problem manifests itself in the consistent overprediction of the number of light precipitation days in GCM simulations (Dai 2006). Here, we test for precipitation biases in CCSM4.

Figure 2 shows the fraction of precipitating days by season in CCSM3, CCSM4, and observations (again, a precipitating day is defined as a day on which $>0.1 \mathrm{~mm}$ precipitation falls). Overall, the spatial distribution of precipitating day fraction in CCSM3 and CCSM4 is similar; both models have more frequent precipitation than is seen in observations. The discrepancy between the models and the observations is particularly large during the winter and spring, when the models have $20 \%-30 \%$ more precipitating days than in observations over the majority of the domain. Notably, the sense of the model error is to overpredict precipitating days over both climatologically dry (southwest United States) and wet (Pacific northwest) regions. Figure 2 shows that precipitation biases, as determined from fraction of precipitating days, are similar in CCSM4 and CCSM3.

\section{c. Precipitation intensity at the 90 th percentile}

Figure 3 shows the 90th percentile value of precipitation intensity, by season, for CCSM3, CCSM4, and observations. The calculation is made by averaging 90th percentile values for individual seasons rather than choosing the 90th percentile value of the entire precipitation distribution. Choosing the former result is more robust, as the latter result could be skewed by a few extreme outlying years.

CCSM4 adeptly simulates the wet tail (i.e., 90th percentile) of the precipitation distribution across the entire domain, except in summer. Notably, during wet seasons, precipitation is most intense in north central California but has the greatest accumulation in 

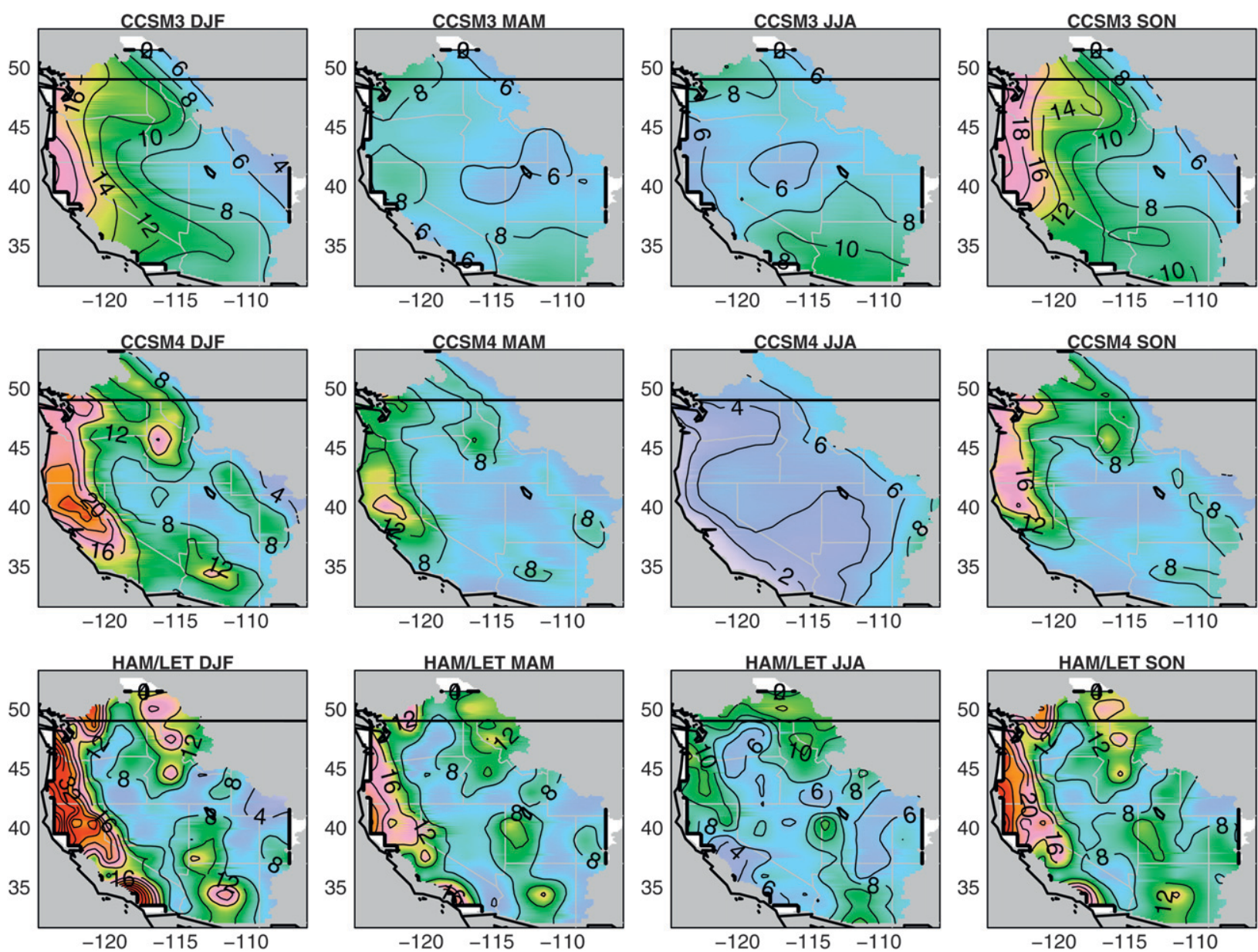

FIG. 3. As in Fig. 1, but for the 90th percentile plot of precipitation intensity (mm day ${ }^{-1}$ ); contour labels are every $4 \mathrm{~mm}^{\mathrm{m}}$ day ${ }^{-1}$. CCSM4 captures observed extreme intensity events over the Sierra Nevada, western Idaho, and central Arizona, which were less resolved in CCSM3.

the Pacific Northwest. The spatial displacement between precipitation intensity and accumulation manifests itself in the observations, and CCSM4 captures this feature quite well.

\section{d. Precipitation duration at the 90th percentile}

Figure 4 shows the 90th percentile value of precipitation duration in days, by season, for CCSM3, CCSM4, and observations. Again, precipitation duration is defined as consecutive strings of precipitating days. The 90th percentile calculation is made as in section $3 c$, except that the 90th percentile value of interest is in units of days rather than millimeters per day.

CCSM4's representation of extreme precipitation duration is markedly improved from that of CCSM3. Precipitation in CCSM3 persisted for several weeks too long during fall and winter, while precipitation duration in CCSM4 is consistent with observations to within several days during those times. When the "precipitating day" threshold is increased from 0.1 to $1 \mathrm{~mm} \mathrm{day}^{-1}, 90$ th percentile precipitation duration values in CCSM3 decrease by about a week, suggesting that much of the persistence bias is occurring on low accumulation precipitation days (not shown). This is an apparent manifestation of the GCM drizzle problem. Although CCSM4 shows an improved simulation of 90th percentile precipitation duration, one notable error is that precipitation persists for too long in regions east of the Cascades, particularly during the summer and fall. In addition, CCSM4 does not reproduce the observed persistency in precipitation over the Pacific Northwest during winter, underestimating the duration of precipitation by several days.

\section{EI Niño-Southern Oscillation and Pacific decadal oscillation}

Aside from its immediate association with climate in the tropics, ENSO also affects the global climate due 

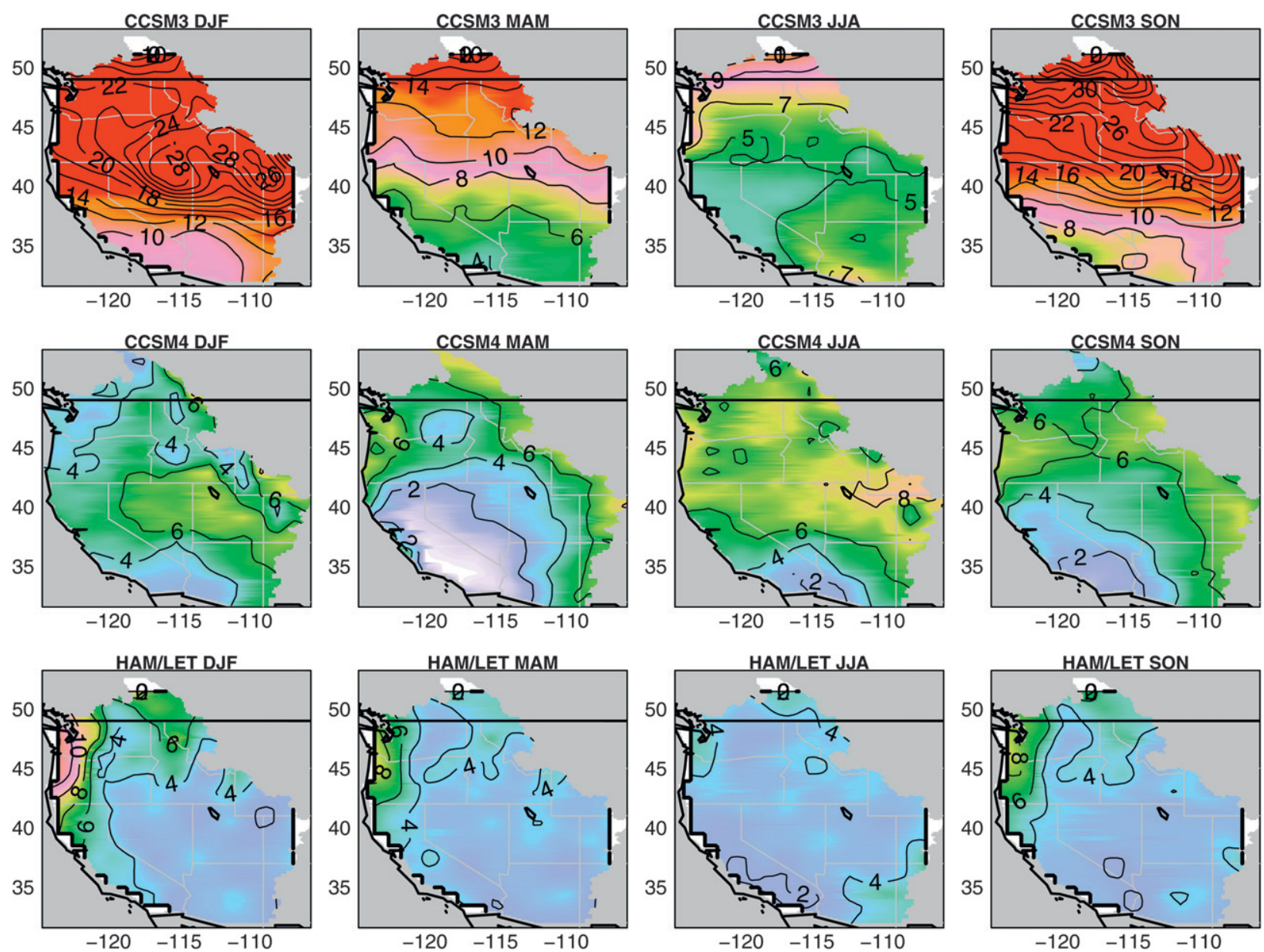

FIG. 4. As in Fig. 3, but for precipitation duration (days; contour labels are every 2 days). CCSM4 drastically reduces the persistent precipitation bias in CCSM3, especially during the winter and spring.

to coupled ocean-atmosphere feedbacks and a redistribution of heat, moisture, and momentum. ENSO shifts the location of the subtropical jet stream, which is the primary determinant of storm tracks over the midlatitudes (Rasmusson and Wallace 1983; Holton 2004). Additionally, it has been shown that the phase of ENSO directly affects the strength and direction of moisture transport from the tropics to the midlatitudes (Dettinger et al. 2004).

Figure 5 shows a Pearson correlation map between the cold-season-averaged [November-March (NDJFM)] principal components (PCs) of the leading EOF of tropical SST anomalies and the cold-season-averaged precipitation anomaly field over the western United States for (a) CCSM3, (b) CCSM4, and (c) observations. The seasonal mean fields are calculated with 1300 years of CCSM4 data, 500 years of CCSM3 data, and 50 years of observed data. CCSM4 captures both the dipole-like structure of the ENSO-precipitation teleconnection and, compared to CCSM3, a stronger magnitude commensurate with the observed pattern over much of the western United States (Gershunov and Barnett 1998). However, the model underestimates the observed eastward extension of moderate positive correlation into Arizona and western New Mexico.

The Pacific decadal oscillation is often defined as the leading EOF of North Pacific SST anomalies and substantially impacts oceanic and atmospheric climate variables (e.g., temperature and precipitation) in both hemispheres (Trenberth and Hurrell 1994; Mantua and Hare 2002). In addition, the PDO has been shown to modulate teleconnected patterns of oceanic and atmospheric circulation associated with ENSO (Gershunov and Barnett 1998; McCabe and Dettinger 1999). Significant peaks in the observed twentieth-century energy spectrum of the PDO have been shown at 50-70-yr and 15-25-yr time scales (Mantua and Hare 2002). Notably, the PDO has not been robustly proven to be a dynamical mode, but rather the superposition of SST variability from multiple dynamical origins (Pierce 2001; Schneider and Cornuelle 2005). 
a) $\operatorname{CCSM} 3$

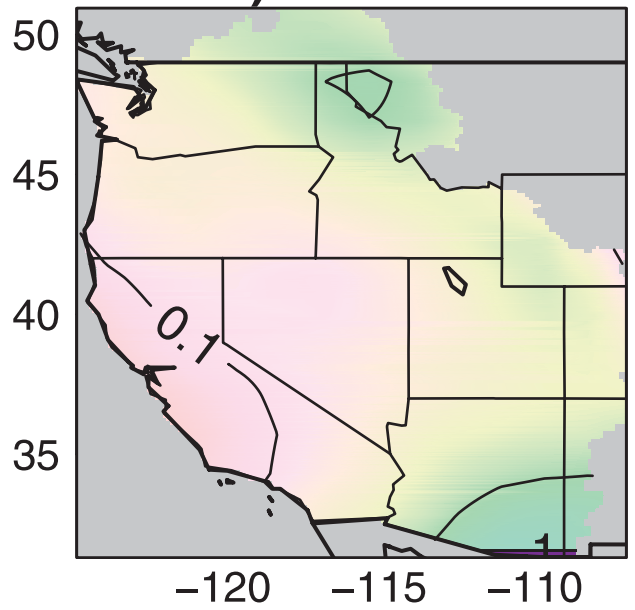

b) CCSM4

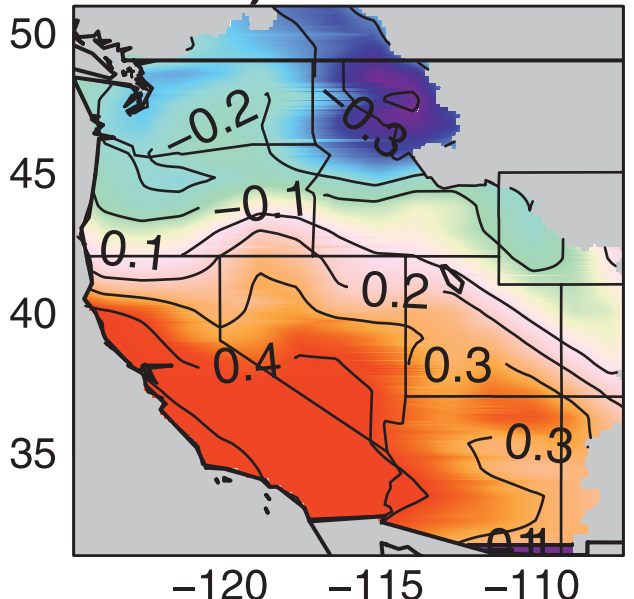

c) OBS

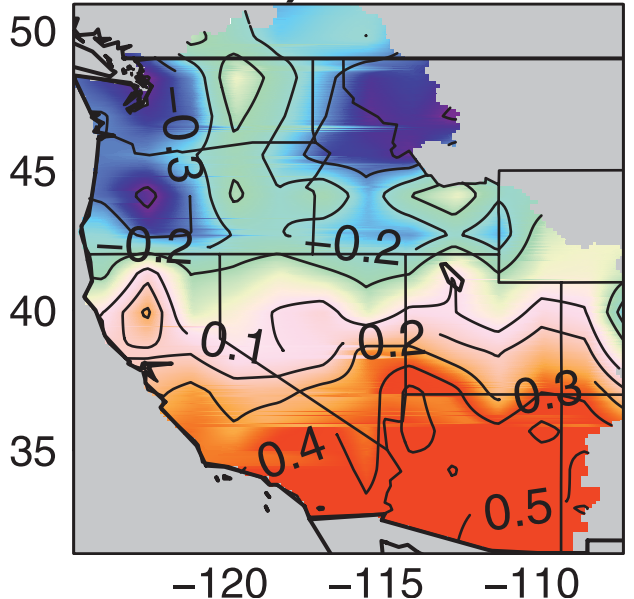

FIG. 5. Pearson correlation map between NDJFM leading ENSO principal components (PCs) and NDJFM precipitation anomalies for (a) CCSM3, (b) CCSM4, and (c) observations.
Figure 6 shows a Pearson correlation map between the cold-season-averaged (NDJFM) PCs of the leading EOF of North Pacific SST anomalies and the coldseason-averaged precipitation anomaly field over the western United States for (a) CCSM3, (b) CCSM4, and (c) observations. The observed correlation map shows that the southern part of the domain experiences enhanced precipitation during positive PDO events, and vice versa, although the values are weak. (Note: positive PDO events are warm along the west coast of North America and cold in the center of the Pacific Ocean). It is important to note the similarity between teleconnected responses of western U.S. precipitation to ENSO (Fig. 5) and the PDO (Fig. 6); that is, the tropical equatorial and North Pacific modes of SST variability in the Pacific are not independent, particularly in CCSM4 (Newman et al. 2003; Deser et al. 2012).

Using the observed teleconnection pattern (Fig. 6c) as a metric, it would be appear that CCSM4's simulation of the teleconnected response of precipitation to PDO SST anomalies is improved compared to CCSM3. However, caution must be taken when comparing results from multicentury model runs to decadal observational records. This is especially true when the signal of interest has a periodicity on the same order of the observed record, as in the case of the PDO. For example, Fig. 7 shows two correlation maps as in Fig. 6, but calculated in independent 50-yr periods of the 1300 -yr run. To illustrate the range of variability, we chose the two 50 -yr periods that were most similar and dissimilar to the observed teleconnection pattern (Fig. 6c). Although the sign of the relationship is consistent, with negative values over the Pacific Northwest and positive values in the Southwest, substantial spatial variability and differences in the magnitude of the correlations exist between the 1300-yr average and the two 50-yr segments. This temporal variation underscores the uncertainty of any particular estimate of the PDO teleconnection derived from a 50-yr observed sample. Ideally, a sufficiently resolved, multicentury North Pacific observational dataset would be needed in order to make meaningful comparisons to multicentury model runs when considering the relationship of the PDO to western U.S. precipitation. In addition, a 50-yr period is not sufficient to define the PDO itself.

\section{Relating extreme precipitation statistics to ENSO and PDO}

We have shown that CCSM4 does an improved job of simulating western U.S. mean and extreme precipitation patterns and the teleconnected signal of ENSO and the PDO to western U.S. precipitation. However, the correlation analyses shown in sections 4 and 5 assume 
a) $\operatorname{CCSM} 3$
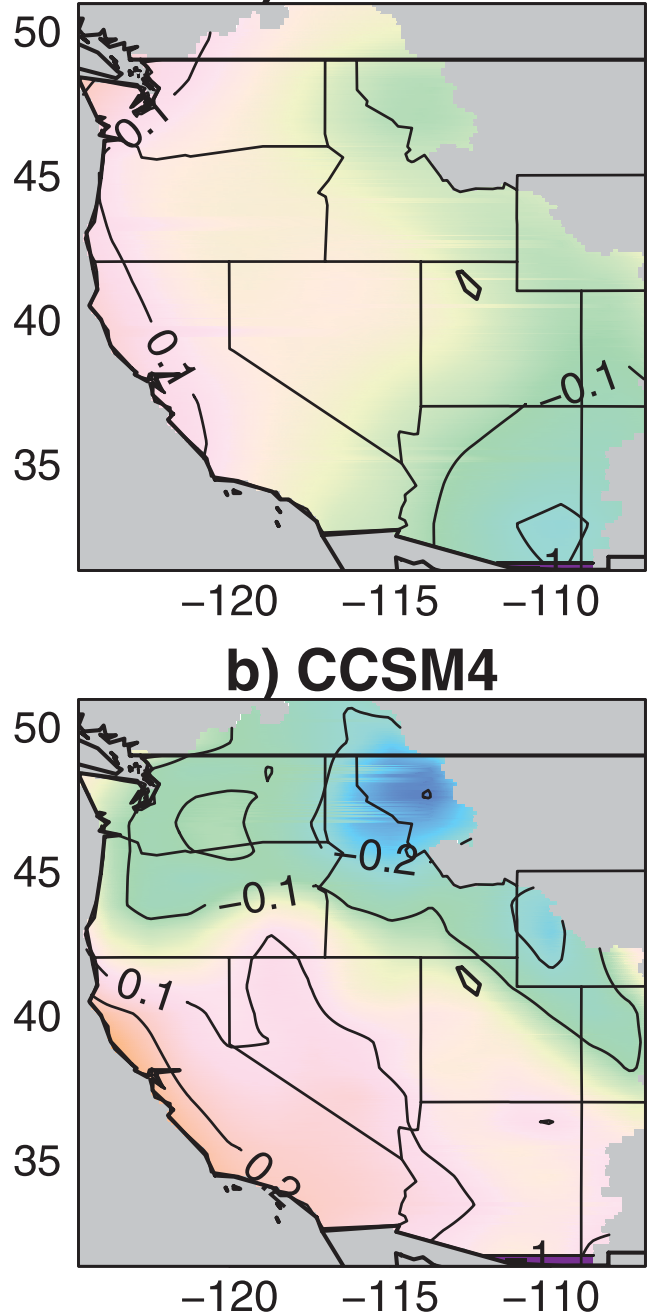

c) OBS

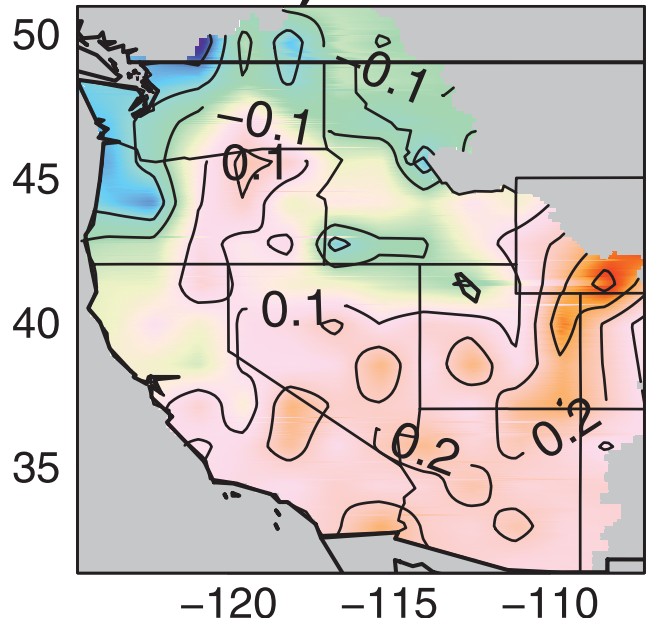

FIG. 6. As in Fig. 5, but between NDJFM leading PDO PCs and NDJFM precipitation anomalies. a linear relationship between precipitation and ENSOPDO. In this section, we employ composite techniques that do not require the assumption of linearity and answer the following questions: What are the characteristics of CCSM4 extreme precipitation statistics on warm and cool ENSO and PDO periods? Are they asymmetric with respect to SST anomalies? How do they compare to observations? We focus on CCSM4 since we have shown that CCSM3 is deficient compared to CCSM4 in the measures of western U.S. precipitation of interest here.

\section{a. Extreme precipitation event composites}

Figure 8 shows tropical and North Pacific surface temperature anomalies composited on wet (top 20th percentile) and dry (bottom 20th percentile) years for (top) CCSM4 and (bottom) observations. The wet and dry periods were determined by calculating annual averages of monthly precipitation anomalies, averaged over a subset of the southwestern United States $\left(32^{\circ}-\right.$ $35^{\circ} \mathrm{N}, 240^{\circ}-250^{\circ} \mathrm{E}$ for $\mathrm{CCSM} 4 ; 34^{\circ}-37^{\circ} \mathrm{N}, 245^{\circ}-249^{\circ} \mathrm{E}$ for observations). Separate regions are chosen for the model and observations based on the positive correlation with ENSO seen in each region in Fig. 2. Based on the results shown in Fig. 2, one would expect tropical Pacific surface temperatures to be anomalously warm during wet periods (or anomalously cold during dry periods) over this subset region. It is evident that this occurs in both the model and observations; that is, the most anomalously warm values of surface temperature occur in the eastern equatorial Pacific in wet years, and vice versa in dry years. However, the model shows an almost completely symmetric response (the composite pattern for wet years is nearly the negative of the pattern for dry years), unlike the observations, which show a more tropical connection for wet years and North Pacific connection for dry years. The model matches the observations in wet years, but in dry years the differences between the model and observations are more pronounced.

This difference between the composite patterns for wet and dry years is shown in the rightmost column in Fig. 8. The magnitude of CCSM4 equatorial Pacific SST anomalies in wet and dry years is greater than observations, reflecting the greater symmetry between wet and dry years found in the model.

\section{b. Precipitation intensity composites}

To investigate the effect of ENSO and the PDO on extreme weather statistics, we composite extreme (90th percentile) wintertime (NDJFM) precipitation intensity on wintertime seasons when the (top) NDJFM ENSO index or (bottom) NDJFM PDO index is warm (leading PC $>0.75$ ) or cool (leading PC $<-0.75$ ). Here, the PC 

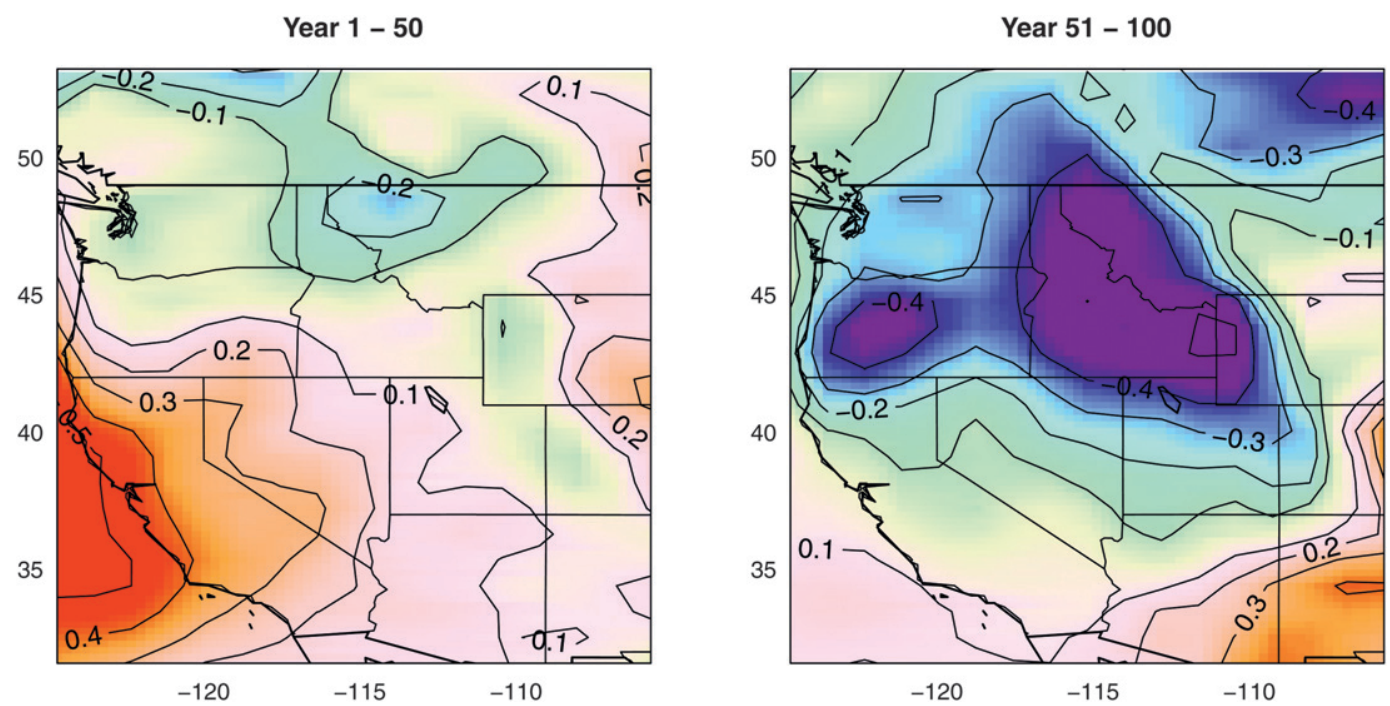

FIG. 7. Pearson correlation map between CCSM4 NDJFM leading PDO PCs and NDJFM precipitation anomalies for two 50-yr partitions: year (left) $1-50$ and (right) $51-100$. There is substantial variability in the spatial pattern.

is standardized and is thus unitless. Note that this analysis differs slightly from those used in section $3 \mathrm{c}$ in that 90th percentile precipitation intensity is calculated for each season (as before); those seasonal values then are composited on warm (leading $\mathrm{PC}>0.75$ ) and cool (leading $\mathrm{PC}<-0.75$ ) ENSO/PDO seasons and averaged. Thus, the calculation methodology is the same, but the compositing step is exclusive to this figure. Precipitation duration composites are not shown here due to the lack of a broad statistically significant relationship.

Figure 9 shows the difference between mean 90th percentile values of NDJFM precipitation intensity $\left(\mathrm{mm} \mathrm{day}^{-1}\right.$ ) composited on warm and cool NDJFM (top) ENSO and (bottom) PDO seasons. Differences significant at the $1 \sigma$ and $2 \sigma(p<0.32$ and $p<0.05)$ levels are shown as dark and light gray shading, respectively. CCSM4 is shown in the left column, while observations are shown in the right column.

The response seen in NDJFM ENSO seasons strengthens three important conclusions drawn from Fig. 8. First, Fig. 9 shows that 90 th percentile precipitation events in the cool season are stronger over the southwest during warm ENSO seasons than during cool ENSO seasons; the opposite is true over the Pacific Northwest. This is roughly consistent with Fig. 8, which shows that warm ENSO conditions are prevalent during extreme wet periods over the southwest, and vice versa during extreme dry periods. Second, as in Fig. 8, Fig. 9 shows that CCSM4 overestimates the magnitude of extreme precipitation events during warm and cool NDJFM ENSO seasons. However, CCSM4 underestimates the observed PDO signal, especially during cool NDJFM seasons. Finally, there is a greater symmetry of the response of extreme precipitation on positive and negative ENSO and PDO phases in CCSM4 than in observations.

The results from Figs. 8 and 9 demonstrate the relationship in CCSM4 between the phase of ENSO (and to a lesser degree, the PDO) and extreme precipitation statistics over the western United States, and underscore the model's exaggeration of this relationship compared to observations.

\section{Discussion and conclusions}

Results shown here demonstrate that, in comparison to CCSM3, the newer CCSM4 version of the NCAR Community Climate Model produces improved simulations of both regional, synoptic precipitation events over the western United States and tropical Pacific (ENSO) and North Pacific (PDO) teleconnections to western U.S. precipitation. We concentrate on the differences between model generations rather than the effects of varying horizontal resolution on model results, although future studies of the latter are required to paint a complete picture of model behavior.

Notably, observed teleconnected signals of equatorial SST anomalies to western U.S. precipitation anomalies are well captured by CCSM4 and represent a substantial improvement from CCSM3. The correlation between PDO SST anomalies and western U.S. precipitation is also well simulated in CCSM4, although the relatively short observational record means that the patterns can differ appreciably due to natural internal climate variability (see Fig. 7).

Over the western United States, CCSM4 captures several important local and regional precipitation features. The climatological pattern of CCSM4 western U.S. 
Wet Years, CcsM4

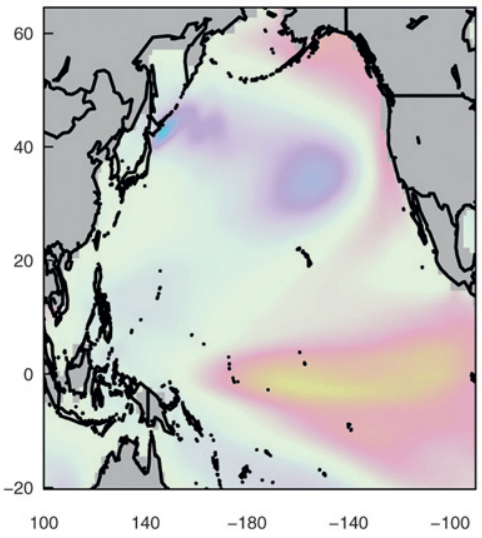

Wet Years, OBS

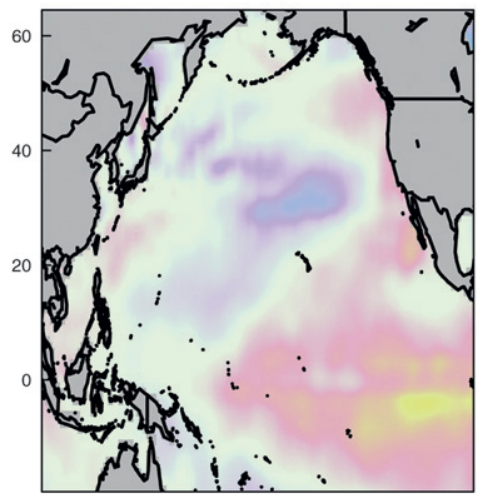

100
Dry Years, CCSM4

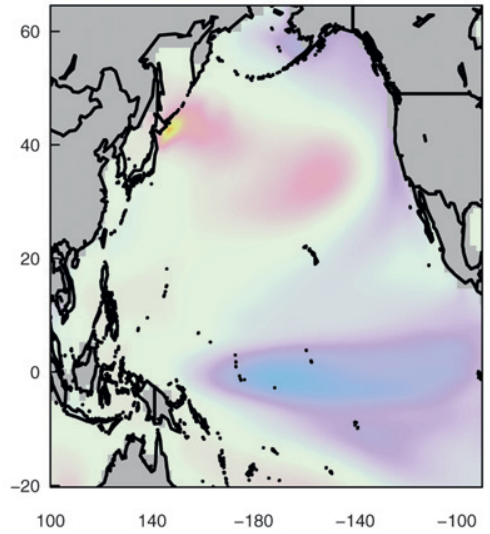

Dry Years, OBS

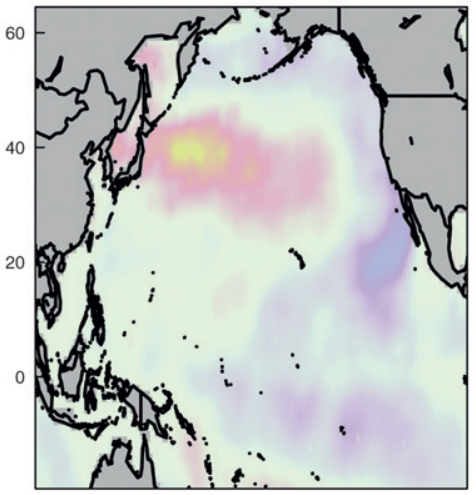

$100-140=-180=-140=-100$
Difference (Wet - Dry), CCSM4

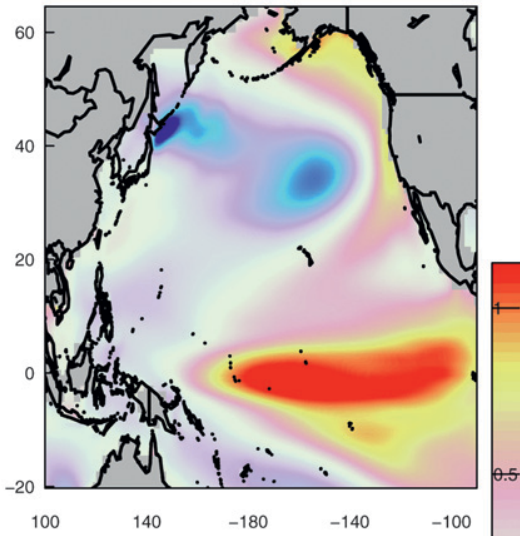

Difference (Wet - Dry), OBS

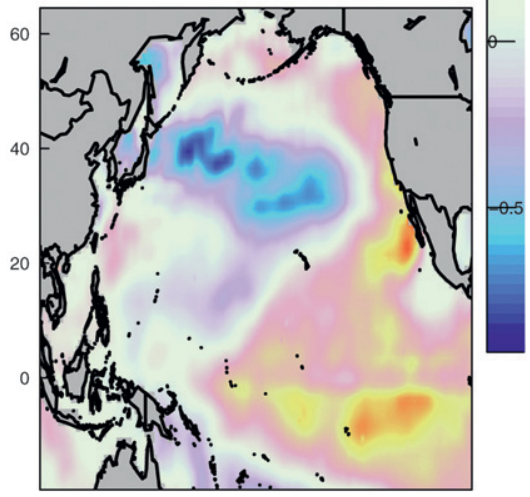

$\begin{array}{llll}100 & 140 & -180 & -140\end{array}-100$

FIG. 8. (top) CCSM4 and (bottom) observed annually averaged (January-December) monthly surface temperature anomalies (K) composited on (left) wet $(>80$ th percentile) and (middle) dry ( $<20$ th percentile) southwestern U.S. years and (right) their difference. There is a strong tropical Pacific SST anomaly signal associated with southwestern U.S. extreme precipitation regimes, particularly on the annual time scale; the signal is stronger and more symmetric in CCSM4 than in observations.

precipitation agrees with that from observations, and the amounts are similar to within several millimeters per day. In comparison to CCSM3, the zonal gradient of precipitation in CCSM4, which is influenced heavily by the Cascade Mountains and Sierra Nevada, is correctly larger over Northern California and the Pacific Northwest. CCSM3's simulation of this gradient was too small, causing precipitation estimates to be smeared eastward across the region. This could be partially due to the fact that CCSM3's horizontal resolution $\left(\sim 1.4^{\circ}\right)$ is slightly coarser than CCSM4's $\left(\sim 1.25^{\circ}\right.$ longitude $\times 0.9^{\circ}$ latitude $)$ in the runs analyzed here, but since the resolutions are close, it is likely that CCSM4 is handling the impact of orography on precipitation more realistically. In addition, the wintertime secondary maximum in precipitation over north central Idaho seen in observations is found in CCSM4, but absent in CCSM3. The displacement between the wettest climatological region (over central Oregon and southwestern Washington) and the most intense storm region (which spreads farther southward) that is seen in observations is captured by CCSM4 during the wet season. Extreme precipitation duration, which was too persistent by several weeks in CCSM3, is now correct in CCSM4 to within several days of observations.

Compositing extreme cold season precipitation metrics on warm and cool ENSO and PDO seasons in CCSM4 revealed that precipitation intensity is particularly sensitive to the phase of ENSO, and that there is a relationship in CCSM4 between the phase of ENSO (and to a lesser degree, the PDO) and extreme precipitation statistics over the western United States.

This study demonstrates that CCSM4 shows many improvements in simulating the teleconnected response of western U.S. precipitation to ENSO and the PDO, and that the model's relationship between ENSO and extreme western U.S. weather statistics is consistent with observations, though too strong. Similar studies 

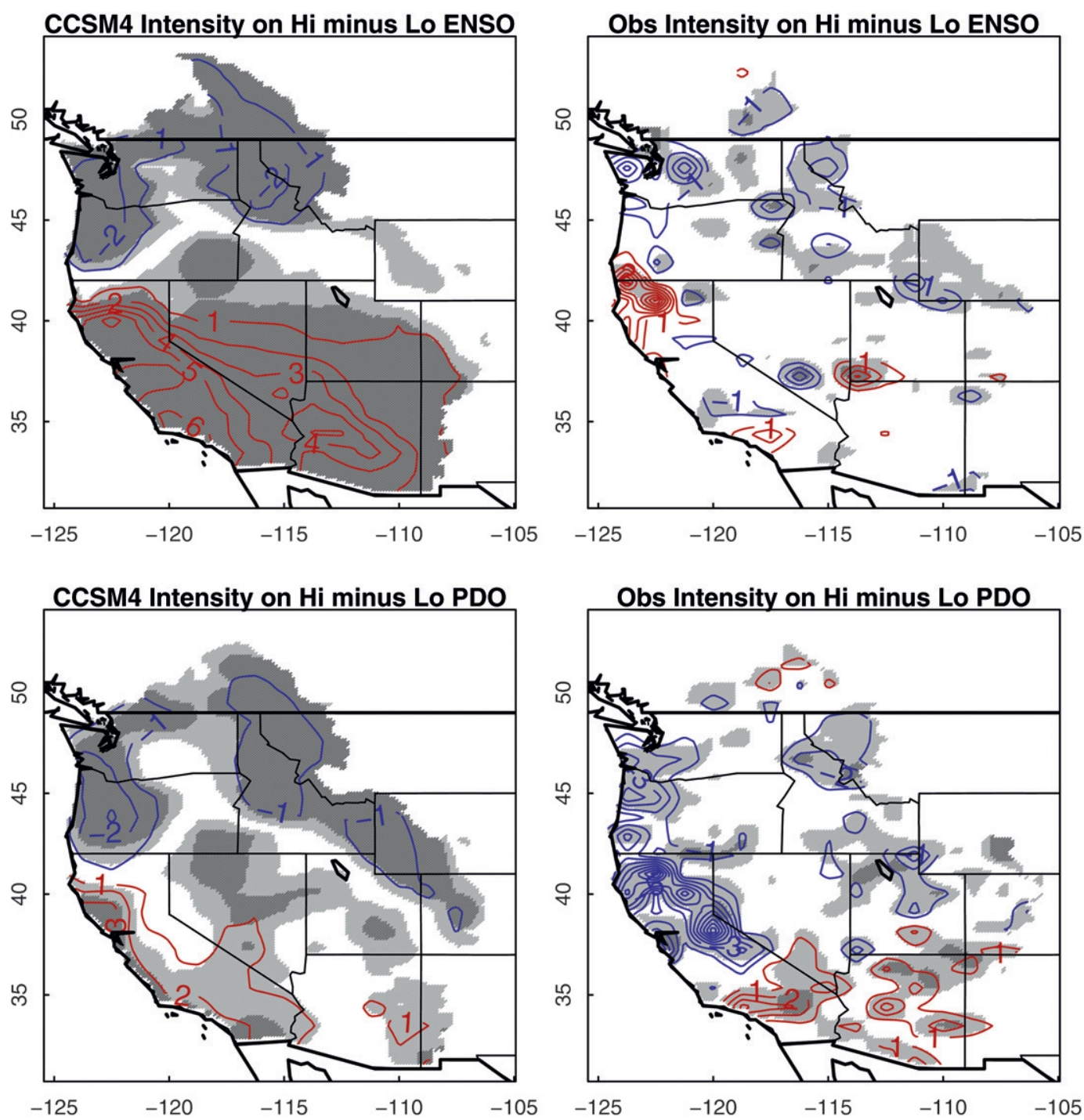

FIG. 9. Difference (warm - cool) of mean 90th percentile value of NDJFM precipitation intensity $\left(\mathrm{mm} \mathrm{day}^{-1}\right)$ on warm (leading PC > 0.75) and cool (leading PC < - 0.75) NDJFM (top) ENSO and (bottom) PDO years, with $95 \%$ (dark gray) and 68\% (light gray) confidence intervals shaded, for (left) CCSM4 and (right) observations Positive values are indicated by red contours, indicating that 90 th percentile precipitation intensity values are higher in warm NDJFM seasons than in cool seasons; the opposite is true for negative values, indicated by blue contours. For ENSO, heavy wintertime (NDJFM) precipitation intensity in CCSM4 is significantly stronger over the southwest during warm ENSO years than in cool ENSO years, and the response is stronger than in observations. This is consistent with expectations from Fig. 8. For the PDO, a similar qualitative pattern to ENSO years exists in CCSM4, but it is weaker. The observations are consistent and show a much stronger cool season signal that extends farther south.

investigating CCSM4's regional climate in other locations could prove useful, so that the consistency of the model dynamics in CCSM4 can be tested across different regions. Studies investigating effects of varying model horizontal resolution may wish to consider how model spatial resolution affects precipitation duration and intensity. On balance, though, the similarity of a range of characteristics of CCSM precipitation to those in observations indicates that the results shown here could provide a basis to understand possible future changes using CCSM4 under greenhouse gas emissions scenarios.

Acknowledgments. This study forms a portion of the Ph.D. dissertation of MJD. Funding was provided by NSF (OCE-0960770 and AGS-1048995), DOE (DE-SC0002000), and NOAA (ECPC: NA17RJ1231). Thanks to Andrew Gettelman (NCAR) for providing information about CCSM4 runs, Alexander Gershunov (SIO) for enlightening discussions regarding North Pacific variability, 
and Stephen Colucci (Cornell University) for theoretical background on midlatitude synoptic storms. We also thank Aneesh Subramanian (SIO) for assistance in accessing the CCSM4 monthly run. Suggestions by three reviewers were very useful in improving the paper.

\section{REFERENCES}

AchutaRao, K., and K. R. Sperber, 2006: ENSO simulation in coupled ocean-atmosphere models: Are the current models better? Climate Dyn., 27, 1-15.

Bjerknes, J., 1969: Atmospheric teleconnections from the equatorial Pacific. Mon. Wea. Rev., 97, 163-172.

Bradley, R. S., H. F. Diaz, G. N. Kiladis, and J. K. Eischied, 1987: ENSO signal in continental temperature and precipitation records. Nature, 327, 497-501.

Cayan, D. R., T. Das, D. W. Pierce, T. P. Barnett, M. Tyree, and A. Gershunov, 2010: Future dryness in the southwest US and the hydrology of the early 21 st century drought. Proc. Natl. Acad. Sci. USA, 107, 21 271-21 276.

Chen, C.-T., and T. Knutson, 2008: On the verification and comparison of extreme rainfall indices from climate models. J. Climate, 21, 1605-1621.

Dai, A., 2006: Precipitation characteristics in eighteen coupled climate models. J. Climate, 19, 4605-4630.

Daly, C., R. P. Neilson, and D. L. Phillips, 1994: A statisticaltopographic model for mapping climatological precipitation over mountainous terrain. J. Appl. Meteor., 33, 140-158.

_ , W. P. Gibson, G. H. Taylor, G. L. Johnson, and P. Pasteris, 2002: A knowledge-based approach to the statistical mapping of climate. Climate Res., 22, 99-113.

da Silva, A. M., C. C. Young, and S. Levitus, 1994: Algorithms and Procedures. Vol. 1, Atlas of Surface Marine Data 1994, NOAA Atlas NESDIS 6, $83 \mathrm{pp}$.

Deser, C., and Coauthors, 2012: ENSO and Pacific decadal variability in the Community Climate System Model version 4. J. Climate, 25, 2622-2651.

Dettinger, M., K. Redmond, and D. Cayan, 2004: Winter orographic precipitation ratios in the Sierra Nevada-Large-scale atmospheric circulations and hydrologic consequences. J. Hydrometeor., 5, 1102-1116.

Gent, P. R., and Coauthors, 2011: The Community Climate System Model version 4. J. Climate, 24, 4973-4991.

Gershunov, A., and T. P. Barnett, 1998: Interdecadal modulation of ENSO teleconnections. Bull. Amer. Meteor. Soc., 79, 2715-2725.

Hamlet, A. F., and D. P. Lettenmaier, 1999: Columbia River streamflow forecasting based on ENSO and PDO climate signals. J. Water Resour. Plann. Manage., 125, 333-341.

$\longrightarrow$, and — 2005: Production of temporally consistent gridded precipitation and temperature fields for the continental United States. J. Hydrometeor., 6, 330-336.

Hidalgo, H. G., and J. A. Dracup, 2003: ENSO and PDO effects on hydroclimatic variations of the upper Colorado River basin. J. Hydrometeor., 4, 5-23.

Holton, J. R., 2004: An Introduction to Dynamic Meteorology. 4th ed. Academic Press, 535 pp.

Lee, J. E., R. Pierrehumbert, A. Swann, and B. R. Linter, 2009: Sensitivity of stable water isotopic values to convective parameterization schemes. Geophys. Res. Lett., 36, L23801, doi:10.1029/2009GL040880.

Mantua, N. J., and S. R. Hare, 2002: The Pacific decadal oscillation. J. Oceanogr., 58, 35-44.
McCabe, G. J., and M. D. Dettinger, 1999: Decadal variations in the strength of ENSO teleconnections with precipitation in the western United States. Int. J. Climatol., 19, 1399-1410.

Meehl, G. A., C. Covey, T. Delworth, M. Latif, B. McAvaney, J. F. B. Mitchell, R. J. Stouffer, and K. E. Taylor, 2007: The WCRP CMIP3 multimodel dataset: A new era in climate change research. Bull. Amer. Meteor. Soc., 88, 1383-1394.

Neale, R. B., J. H. Richter, and M. Jochum, 2008: The impact of convection on ENSO: From a delayed oscillator to a series of events. J. Climate, 21, 5904-5924.

, J. Richter, S. Park, P. H. Lauritzen, S. J. Vavrus, P. J. Rasch, and M. Zhang, 2013: The mean climate of the Community Atmosphere Model (CAM4) in forced SST and fully coupled experiments. J. Climate, in press.

Newman, M., G. P. Compo, and M. A. Alexander, 2003: ENSOforced variability of the Pacific decadal oscillation. J. Climate, 16, 3853-3857.

Parker, K., cited 2010: Population, immigration, and the drying of the American Southwest. Center for Immigration Studies. [Available online at http://www.cis.org/southwest-waterpopulation-growth.]

Pierce, D. W., 2001: Distinguishing coupled ocean-atmosphere interactions from background noise in the North Pacific. Prog. Oceanogr., 49, 331-352.

, 2002: The role of sea surface temperatures in interactions between ENSO and the North Pacific Oscillation. J. Climate, 15, 1295-1308.

Ralph, F. M., 2012: Water supply and flooding. California Climate Extremes Workshop report, D. W. Pierce, Ed., Scripps Institution of Oceanography, 8-9. [Available online at http:// meteora.ucsd.edu/cap/pdffiles/CA_climate_extremes_report_ SIO_Dec2011.pdf.]

Rasmusson, E. M., and J. M. Wallace, 1983: Meteorological aspects of the El Niño/Southern Oscillation. Science, 222, 1195-1202.

Reynolds, R. W., N. A. Rayner, T. M. Smith, D. C. Stokes, and W. Wang, 2002: An improved in situ and satellite SST analysis for climate. J. Climate, 15, 1609-1625.

Ropelewski, C. F., and M. S. Halpert, 1986: North American precipitation and temperature patterns associated with the El Niño/ Southern Oscillation (ENSO). Mon. Wea. Rev., 114, 2352-2362.

Saillant, C., 2010: Homeowners forced to buy flood insurance after FEMA redraws maps. Los Angeles Times, 4 January. [Available online at http://articles.latimes.com/2010/jan/04/local/ la-me-flood-maps4-2010jan04.]

Schneider, N., and B. D. Cornuelle, 2005: The forcing of the Pacific decadal oscillation. J. Climate, 18, 4355-4373.

Solomon, S., D. Qin, M. Manning, Z. Chen, M. Marquis, K. Averyt, M. M. B. Tignor, and H. L. Miller Jr., Eds., 2007: Climate Change 2007: The Physical Science Basis. Cambridge University Press, $996 \mathrm{pp}$.

Trenberth, K. E., 1976: Spatial and temporal variations of the Southern Oscillation. Quart. J. Roy. Meteor. Soc., 102, 639653.

- and J. W. Hurrell, 1994: Decadal atmosphere-ocean variations in the Pacific. Climate Dyn., 9, 303-319.

Wehner, M. F., R. L. Smith, G. Bala, and P. Duffy, 2010: The effect of horizontal resolution on simulation of very extreme US precipitation events in a global atmosphere model. Climate Dyn., 34, 241-247.

Zhu, C., D. W. Pierce, T. P. Barnett, A. W. Wood, and D. P. Lettenmaier, 2004: Evaluation of hydrologically relevant PCM climate variables and large-scale variability over the continental U.S. Climatic Change, 62, 45-74. 